\title{
What is mixed use? Presenting an interaction method for measuring land use mix
}

\author{
Kevin Manaugh ${ }^{a}$ \\ Tyler Kreider \\ McGill University \\ McGill University
}

\begin{abstract}
In recent decades, the mixing of complementary land uses has become an increasingly important goal in transportation and land use planning. Land uses mix has been shown to be an influential factor in travel behavior (mode choice and distance traveled), improved health outcomes, and neighborhood-level quality of life. However, quantifying the extent to which a given area is mixed-use has proven difficult. Much of the existing research on the mixing of land uses has focused on the presence and proportion of different uses as opposed to the extent to which they actually interact with one another. This study proposes a new measure of land use mix, a land use interaction method-which accounts for the extent to which complementary land uses adjoin one another-using only basic land use data. After mapping and analyzing the results, several statistical models are built to show the relationship between this new measure and reported travel behavior. The models presented show the usefulness of the approach by significantly improving the model fit in comparison to a commonly-used land use mix index, while controlling for socio-demographic and built form factors in three large Canadian cities (Vancouver, Toronto, and Montreal). Our results suggest that simple, area-based, measures of land use mix do not adequately capture the subtleties of land use mix. The degree to which an area shows fine-grained patterns of land use is shown to be more highly correlated with behavior outcomes than indices based solely on the proportions of land use categories.
\end{abstract}

\section{Introduction}

The idea of maximizing — and measuring — the extent to which the built form can encourage active transportation has become a key issue for planners. Increased pedestrian and cycling activity potentially offers an easy and cost-effective manner to improve human health, limit the adverse effects of transportation-related pollution, and increase neighborhood interaction and sense of place (Wilkinson and Marmot 2003). For these reasons, many regional and municipal transportation plans now place a focus on providing communities where walking is a viable alternative to the car. Many municipalities make the goal of mixing land uses an explicit part of land use plans (for example: City of Montreal 2005; City of Toronto 2006; City of Los Angeles 2008). In fact, land use mix plays a central role in major urban planning and design concepts (Smart Growth, New Urbanism, TOD). However, "mixed-use", for the most part, remains an elusive, intangible concept. As Handy (2008) has shown, goals that do not have clear indicators to measure success, can often lose priority in the planning or implementation process to more easily measured goals.

The link between land use mix and travel behavior has been widely studied. The concept is simple enough: while a large, single-use residential area will often require residents to use motorized transportation to reach employment, commercial, or leisure destinations, a fine-grained mixing of residential, commercial, and recreational land uses might allow local residents to walk or bike to desired destinations. However, despite being a foremost concern for planners and policy makers, many existing methods to measure the extent to which an area is mixed rely on ungrounded assumptions. This paper proposes a new method of measuring land use mix using only basic land use data and GIS techniques. By measuring the extent to which complementary land uses actually interact with one another, it is argued that this method more accurately describes the degree of land use mix in a given area.

This research provides a new tool that can aid researchers and practitioners in studying the links between transportation and land use. The thesis put forth in this paper is that a measure that depends on proportions of various land uses in a given area misses a key point: two areas could have identical proportions of land uses, yet be distributed in vastly different ways, meaning that giving them a similar land use "score" could be extremely misleading. This work has relevance not only for travel behavior research, but also for wider inquiry into sprawl and Smart Growth, for example. As the health benefits of walking and cycling are well documented (Rippe, Ward et al. 1988; Murphy, Nevill et al. 2002), the connections to the type of de-

a kevin.manaugh@mail.mcgill.ca 
velopment patterns that might support these activities are vital.

Let us take a slightly over-simplified example to introduce the concept. Imagine three different neighborhoods with roughly 33 percent each of residential, commercial, and park/ recreational land use. In the first neighborhood, a single-use residential area borders a park which, in turn, borders a large commercial area. The second neighborhood, however, distributes the same proportion of land uses in a more fine-grained manner. The third exhibits an even more fine-grained mix of uses, with almost every parcel of each land-use lying adjacent to another complementary use. The assumed distance to either a commercial and recreational destination from any given residential location is much smaller in $\mathrm{B}$ or $\mathrm{C}$ than in the $\mathrm{A}$. In fact, one could argue that B is "twice as mixed" as A as the average distance from any residential parcel to either commercial or recreational land use is roughly half of that in A. While these would score identically in an index based solely on proportions of land use, the transportation implications of each could be drastically different. This is illustrated in Figure 1.
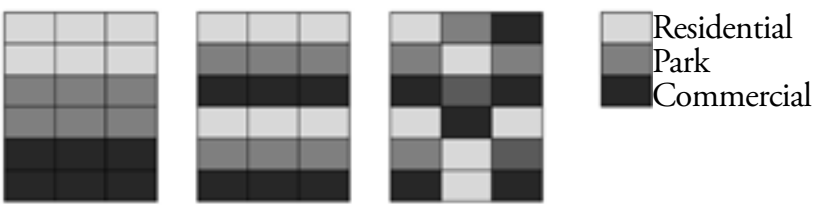

Figure 1. Three different mixes of land uses that would score identically in an entropy mix of land uses.

Therefore, the goals of this research are 1) to develop and present a land use interaction measure using only basic GIS techniques and land use layers and 2) to evaluate this measure by examining its relationship with reported walking and biking behavior. This study presents a relatively straight-forward GIS-based methodology that arguably captures the travel implications of land use patterns in a more effective and meaningful way. By taking into account the proximity and location of complementary land uses, this new measure is expected to better explain the extent to which an area has mixed land uses.

\section{Background}

As the literature on measuring land use mix is vast, this review will focus on the most prevalent methods in order to evaluate our proposed approach. One of the most common indices of measuring land use mixing comes from outside the fields of geography and urban planning: the entropy index. This measure has been in used to study biodiversity and is used in fields as varied as ecology and communication and can be traced to the work of Shannon (1948). Its use in urban planning and land use studies goes back at least as far as Frank and Pivo (1994), who used a version of this index in a classic mode choice study, which found that walking, biking and transit trips were positively correlated with the measure. The entropy index can be expressed as:

$$
\frac{-\sum\left(A_{i j} \ln A_{i j}\right)}{\ln N_{j}}
$$

Where:

- $A_{i j}=$ Percent of land use $i$ in census tract $j$

- $N_{j}=$ Number of represented land uses in census tract $j$

Many variations exist as to how land uses are grouped. For example, Frank and Pivo (1994) divided retail, office, entertainment, and institutional into separate groups and penalized for the existence of single family homes while giving positive values for multi-family homes. However, other work has used more general land use categories (i.e., residential, commercial, and park). This is also dependant on the availability of detailed land use maps. In addition, this index has been studied at many geographical scales, including different census aggregations, metropolitan regions, and buffers around individual households.

A related measure, the Herfindahl index (sometimes Herfindahl-Hirschfield, or HHI) has its roots in economic analysis and is defined as a concentration measure. It has been cited in studies dealing with monopoly situations in the marketplace and industry concentration (Ordover, Sykes et al. 1982). The Herfindahl index is simply the sum of squares of the proportion of different component parts. For example, an area with five equally distributed land uses ( $20 \%$ each) would score a 2,000 out of a possible 10,000 . An area of only one land use would score a 10,000.

While the two equations vary in appearance, Van Eck \& Koomen (2008) found that the entropy and Herfindahl index are virtually indistinguishable when standardized and mapped. For the sake of simplicity, we are only comparing the entropy index in this study. The Herfindahl index has been used in a number of studies, including recent research on the influence of built form factors on pedestrian injury severity levels (Clifton, Burnier et al. 2009).

Past research has, in fact, addressed some of the assumptions made in using these indices. For example Hess, Moudon et al. (2001) identify three main issues with any mixed use measure based solely on proportions of various uses: 1) land use types are not differentiated - a perfect mix of industrial and park might score identical to the same proportions of residential and commercial; 2) a measure of proportion misses any sense of interaction (whether they are adjoining or separated by barriers of some sort); and 3) 
reversing the proportions of land use (i.e., 30 percent residential and 70 percent commercial to 30 percent commercial and 70 percent commercial) would have no effect on the entropy or Herfindahl score even though the travel implications of the two patterns could certainly be quite different.

Finally, and related to the last point above, while it might seem to initially make intuitive sense, we question the fact that an even land use split is considered superior to an uneven one. For example, two land uses split 50/50 would score higher than a mix of 65/35. Previous work has in fact referred to this even mix as a "perfect" land use mix (Rajamani, Bhat et al. 2003, among others). To our knowledge, the literature seems to be lacking in a real theoretical underpinning of this key point. That there is a link between land use mix and behavior has become relatively widely accepted. For this reason, land use mix has become a central goal of municipal plans, and a key aspect of such design paradigms as Smart Growth, New Urbanism, and transit-oriented development. In addition, these problematic manners of measuring mix play a central role in common walkability indices (Lee and Moudon 2004; Frank, Schmid et al. 2005; Lee and Moudon 2006) Therefore, it is absolutely vital that this elusive concept is measured as accurately as possible.

A particularly good example of a partial solution to some of the above issues is found in Rajamani et al. (2003). The authors utilize a series of distribution quotients that take into account the ratio of each land use to the number of housing units in the neighborhood. They also use a slightly modified land use diversity index proposed by Bhat \& Gossen (2004). However, this modified land use diversity index suffers from many of the same shortcomings by focusing on land use proportions without controlling for interaction.

Other methods exist to attempt to capture the elusive qualities of land use mix; however, as these measures, particularly the entropy index, are so widely used, this brief literature review focused on them. Kockelman (1997), in an influential study, used both the entropy measure and introduced a "dissimilarity index" which values the extent to which adjoining land differs in use, (see also (Cervero and Kockelman 1997)). However, while sharing similar concerns to our own, this measure works at an aggregate grid cell level based on the most prevalent land use in a given cell, and therefore misses the actual extent to which the distinct uses interact. In addition, this measure does not take into account the actual type or extent of mixing; it only measures whether adjoining grid cells differ from a central cell. A study of health and obesity outcomes related to the walkability of respondents' neighborhoods, found that the presence of certain land uses at a walkable distance explains much more behavior than the relative proportion or mixing (Brown, Yamada et al. 2009). Brownson, Hoenher et al. (2009) offer a thorough review of previous studies on the correlations between land use mix and other neighborhoodlevel characteristics and travel behavior.

Other authors have used simple binary measurements of land use presence. Kerr, Frank et al. (2007), in addition to a land use mix index, used dummy variables for any commercial use and any recreation/park use. Interestingly, these binary variables were found to have both a higher coefficient and significance level with physical activity than the land use mix measure. On the other side of the spectrum, some previous work has looked at completely disaggregated land uses based on parcel-level data or point-level business and retail information (Hess, Moudon et al. 2001). While we acknowledge that these methods can be extremely accurate, particularly in measuring vertical mixing of land uses, the data is often difficult to access and can be data-intensive and time-consuming with which to work. The method proposed here uses basic land use layers that are widely available in most academic and municipal contexts.

It should be noted that, despite the potential issues mentioned above, these land-use measurements have successfully been linked to behavior and health outcomes. For example, researchers have found a correlation between entropy measures of land use mix and increased physical activity (Kockelman 1997; Cerin, Leslie et al. 2007; Frank, Sallis et al. 2009). A detailed review of the link between land use and transportation is provided by Badoe and Miller (2000) who found that land use mix, along with other built form variables, is often found to significantly influence automobile use, albeit sometimes with a very weak effect. They also recognize, however, that gaps exist in this area of the literature, and make specific mention of weaknesses in data and methodology.

\section{Methodology and data}

Since our goal is to compare two measures of land use, the first step of this research involves generating the entropy score and the proposed interaction measure in Canada's three largest metropolitan regions. In order to calculate the two different measures of land use mix, land use maps from Ontario, Quebec, and British Columbia, developed by DMTI Spatial (2007), were used in a geographic information system (GIS) which allows the measurement and manipulation of spatial data. This work was undertaken using ESRI ArcMAP version 9.3. These maps use seven categories to describe urban land use: residential, commercial, institutional and governmental, resource and industrial, park and recreational, 
open area, and water. This dataset was chosen for several reasons. As this data is available and consistent throughout the country, it was seen to be an ideal source to compare both land use patterns and travel outcomes on a wide scale. Other, finer scale datasets were considered for parts of the Montreal metropolitan region, but as these were not available to us for the three regions under study, thus the more general seven-category land use data was chosen. In addition, this broad data was used for the express purpose of demonstrating that a more accurate measure of land use mix can be generated using readily-available data. It is recognized that different data sources may yield varying results.

Additional data were collected at the census tract level in the metropolitan regions of Toronto, Montreal, and Vancouver from Statistics Canada (StatsCan 2006). These variables include population density, percentage of population under 35 years old, percentage of dwellings built before 1946, median household income, and percentage of residential dwellings that are single-detached. Census tracts were used as they are designed to approximate neighborhoods and therefore an appropriate size to measure land use mix, yet small enough that a sufficient number exist in each metropolitan area for statistical modeling with significant local variation.

In order to preserve continuity with the theory behind land use mix and only compare measures that differ in method, three categories were defined from the land use dataset. The underlying assumption of this research is that shorter travel distances-allowing active transportation choices_can be generated by the mixing of complementary land uses. In order to operationalize this for this study, we have divided the seven land uses into three categories. Residential was left as its own category; commercial, institutional and governmental, and resource and industrial were collapsed into a second category to represent commercial and employment destinations within each census tract; and park and recreational was collapsed with water into a third category to represent opportunities for leisure

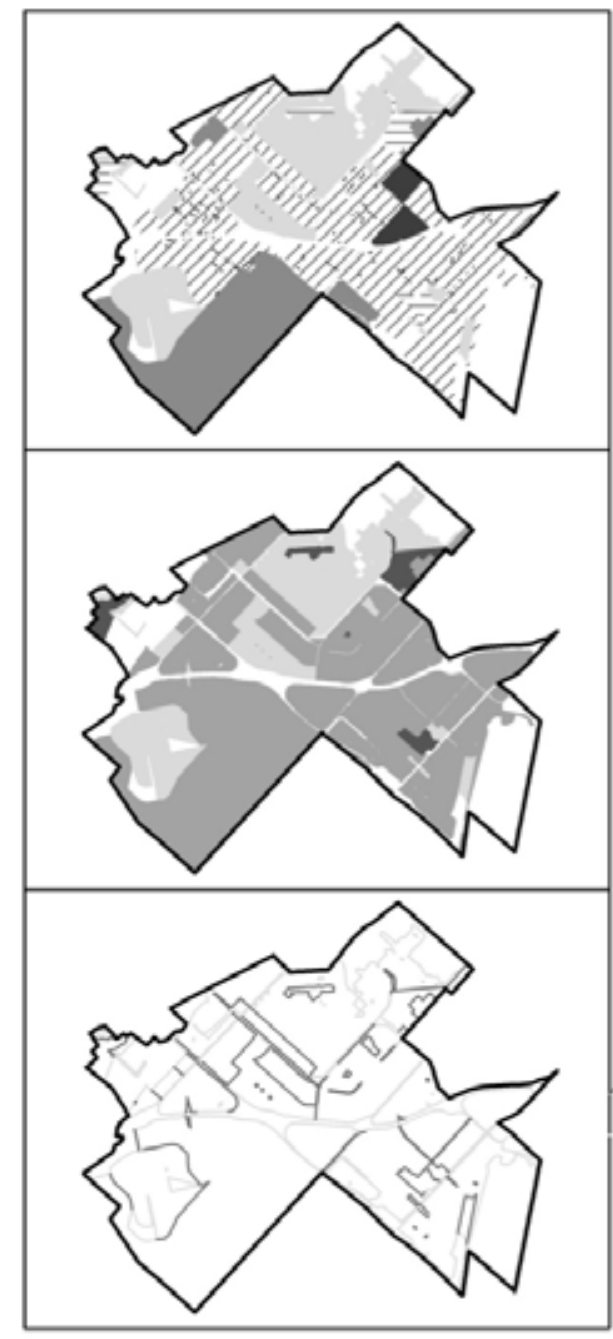

Figure 2 Interaction method procedure

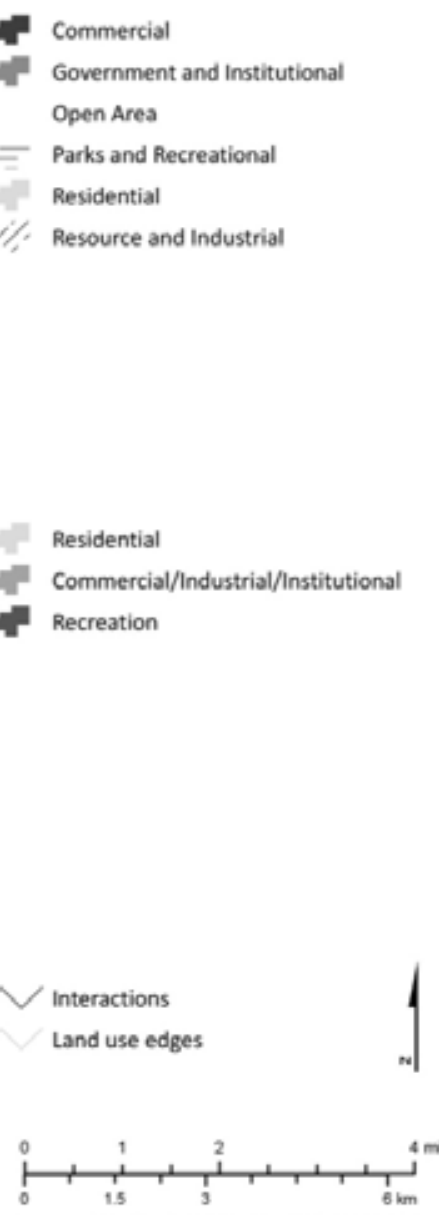

Sources: DMT Spatial Projection: NAD 1983 MTM 8 
and recreation. Open areas were removed from the dataset, as unused space is not expected to contribute to land use mix. Although this method of categorization may differ from that used in some previous studies that measure land use mix using the entropy index (Frank and Pivo 1994), one reason for doing so was so that better land use scores would be given to census tracts containing all three categories, rather than penalizing for the lack of more specific categories (such as institutional and governmental). In addition, the three-group approach presented here does have a precedent (Bhat and Gossen 2004). Importantly, this approach does not count interaction between industrial and government, for example, as a complementary mix. The intention is to capture those areas where the mixing of residential, commercial and economic, and recreational uses would be thought to lead to the potential of active transportation.

The entropy index was calculated using the three land uses described above. The formula used can be found in the
Background section. The result was a number assigned to each census tract ranging from 0 to 1 , where 1 is a perfect mix and 0 comprises only 1 use (or entirely open area). The standardized Z-score of this value was then calculated so that results using the entropy method would be comparable with that using the interaction method described below.

The interaction method proposed here uses the same land use data as were used to generate the entropy index. The land use dataset is represented by polygons. These polygons are then converted into lines using basic GIS tools, representing the interactions between two distinct uses. The only interaction lines that are preserved, however, are those between two complementary uses, meaning that boundaries between any use and open area are eliminated. The total lengths of these interaction lines are determined for each census tract, and this value is divided by the area of the census tract, minus open space. As was done for the entropy index, the Z-score is calculated based on the mean and standard deviation of interaction length per

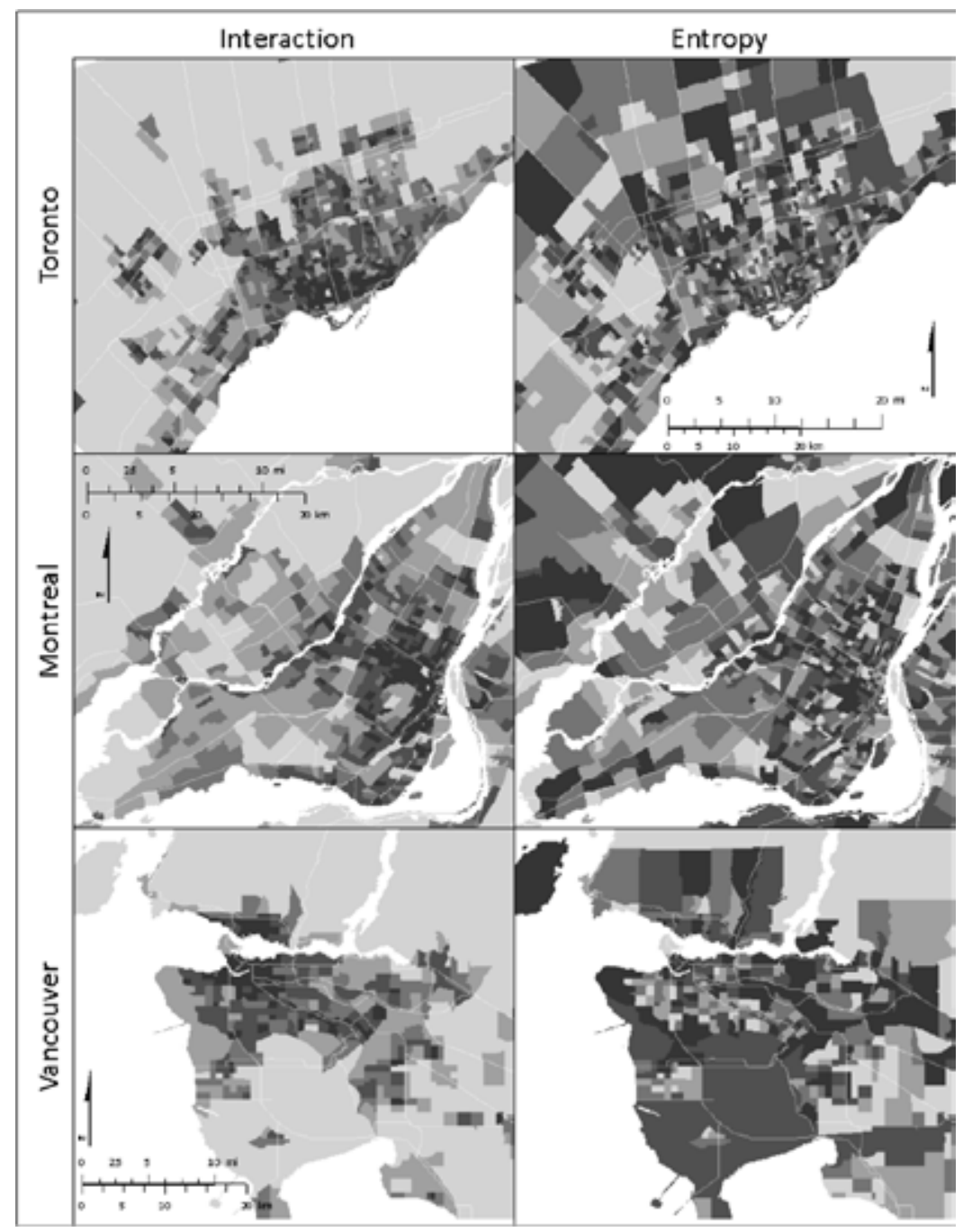

Figure 3 Z-scores of entropy and interaction methods for the three metropolitan areas 


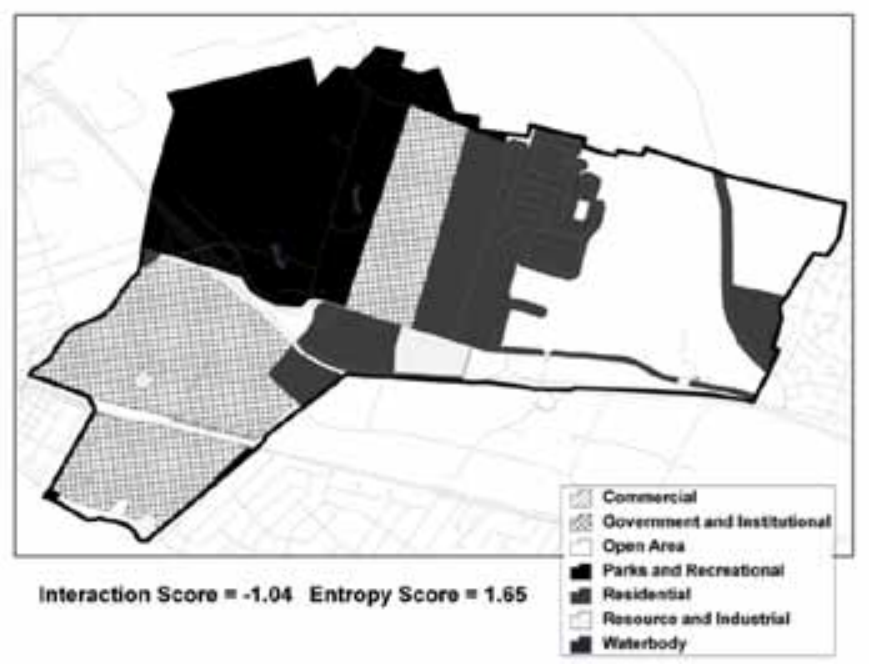

Figure 4 Close-ups of two census tracts showing methodological discrepancies

area. In this manner, a census tract with residential and commercial uses adjoining one another will score higher than one with these land uses being distant.

The series of maps shown in Figure 2 present a general image of the steps taken in generating the interaction measure. The uppermost image shows a close up of a single census tract in Montreal with the original land use data. The middle image shows these land uses dissolved into three general categories: residential; commercial, government and institutional, and resource and industrial; and park and water. The final image shows both the interaction between complementary land uses and the land use boundaries that were discarded. In this way, the interaction between residential land use and commercial activity is counted, while residential land use adjoining open space is not.

\section{$4 \quad$ Initial findings}

Using the Z-score of the entropy index and the land use mix value generated from the interaction method, six chloropleth maps were generated to visually compare the outcomes from each method in Toronto, Montreal, and Vancouver. The method used for classification in the maps was quintile (five equal classes). Thus, the maps are easily comparable across measures and regions. As can be seen in Figure 3, the two maps vary dramatically. The entropy index is displayed in a seemingly random manner, with many census tracts in the far peripheries of the cities having very high entropy index scores. Initial visual inspection seems to confirm the usefulness of the interaction approach, as the left hand side agrees with subjective experience of the three cities. This initial mapping seems to confirm some of the issues present in the entropy measure, however, this will need to be statistically validated in

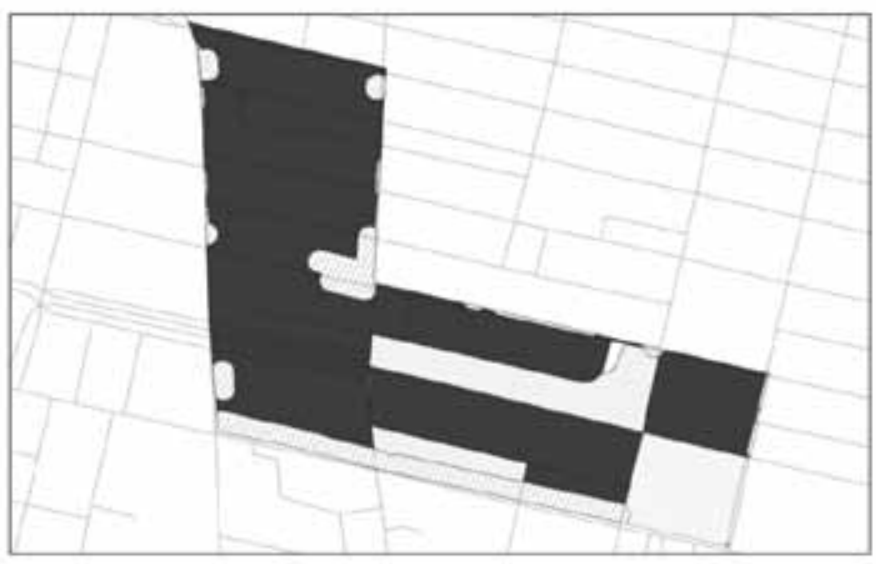

Interaction Score $=2.32$ Entropy Score $=-0.23$

order to understand its usefulness.

Before presenting a statistical analysis of this measure, a comparison map is shown to highlight the potential usefulness of this approach. Figure 4 shows two census tracts in the Montreal region: the first scores high on the entropy measure and quite low on the interaction method, while in the second map, the opposite is true (Note: Z-scores are shown; these essentially measure the number of standard deviations away from the mean, in other words, the uppermost area scores well below average using the interaction approach and well above average using the entropy method). While the top does have a mixing of land uses, both their type and geographic location would arguably not have the same travel implications as in the lower figure where, although the proportion of land uses might not be even, their proximity to one another could have a major effect on daily travel behavior. For example, nearly every residential location in this census tract is within an 800 meter walk of a commercial land use, while in the first figure, residential land is separated from the park by a large institutional land use. Importantly, the lack of actual interaction between these large areas of institutional, residential, and park is reflected in the low score in the interaction method, but the entropy measure overestimates the mixing of uses by only using the relative proportions of land use.

\section{Statistical application}

\subsection{Model Specification}

In order to test the validity of the proposed method of measuring land use mix (the interaction method), a series of simple OLS models are designed. The unit of analysis is the census tract as defined in 2006, and the dependent variable in these 
models is the percentage of people who use walking or bicycling as their primary mode of transportation to work. While many studies have studied the expected negative effect of land use mix on automobile use (see Badoe and Miller (2000) for a review), walking and biking were chosen in this model so that transit accessibility would not be a necessary variable in the models. This allows for models that utilize only data readily available from the Canadian census. The independent variables chosen for the model are a group of variables that have been shown in the literature to be associated with travel behavior at the neighborhood scale.

Population density is measured as the number of people per square meter. Age is represented by percentage of the population under 35 years of age. This is chosen to account for areas that have a high amount of young people, which could be expected to increase levels of walking and cycling. Socioeconomic status is measured using median household income, measured in units of $\$ 10,000 \mathrm{CAD}$. Finally, two additional urban form variables (aside from land use mix) are examined. The first is percentage of housing stock that was built before 1946, which serves as a proxy for neighborhood characteristics such as street grid pattern. The other is the percentage of housing stock that is single-detached, a variable often used in travel behavior studies (Boarnet and Greenwald 2000) and here hypothesized to lead to decreased active transportation. This data is obtained from the 2006 census of Canada (StatsCan 2006). It is recognized that the dependent variable used in this paper is not ideal as a measurement for the amount that people actually walk or bike, but it is used here due in part to lack of data other than those from the census but also to demonstrate the applicability of land use mix in a model using only readily available data. The literature has shown, in fact, that neighborhood-level land-use mix could have more of an effect on non-work trips. However, as the intention is to show a large-scale application of the new land-use mix measure, using widely available census data was seen as the best solution and future work is planned to test this measure on a smaller scale using, for instance, actual pedestrian counts on individual street segments and origindestination surveys. In addition, other travel outcomes, such as the percentage of people who take transit, are highly correlated with transit accessibility and reliability and were seen to be out of the scope of this study.

To examine the effect of the two land use mix variables on modeling the degree to which people walk or bike, the entropy index and interaction method are used for the three most populous metropolitan areas in Canada: Toronto, Montreal, and Vancouver. Three models are built for each of the cities. The first model uses the dependent variables described above without a land use mix variable, the second model em- ploys the entropy index, and the third model introduce the interaction method. With these nine models, it is possible 1) to identify the differences in explanatory power between entropy and interaction, and 2) to observe the differences among the three metropolitan areas under study in determinants of travel behavior. It should be noted here that all variables are included in all models even if a better model could be achieved by omitting variables. This is in order to show the differences between cities in terms of what affects travel behavior.

Table 1 Descriptive Statistics of Model Variables

\begin{tabular}{|c|c|c|c|c|c|c|}
\hline \multirow{2}{*}{ Variable } & \multicolumn{2}{|c|}{ Toronto } & \multicolumn{2}{c|}{ Montreal } & \multicolumn{2}{c|}{ Vancouver } \\
\cline { 2 - 7 } & $x$ & $s$ & $x$ & $s$ & $x$ & $s$ \\
\hline Walk/bike (\%) & 6.03 & 7.88 & 9.03 & 8.95 & 6.40 & 7.33 \\
\hline $\begin{array}{c}\text { Pop. Density } \\
(/ \mathrm{m} 2)\end{array}$ & 0.0050 & 0.0050 & 0.0057 & 0.0052 & 0.0041 & 0.0041 \\
\hline$<35$ years (\%) & 44.48 & 6.45 & 39.84 & 6.04 & 42.72 & 5.91 \\
\hline Pre-WWII (\%) & 11.15 & 20.04 & 15.29 & 20.05 & 7.67 & 11.76 \\
\hline $\begin{array}{c}\text { Income } \\
(\$ 10,000)\end{array}$ & 6.95 & 2.59 & 5.12 & 2.22 & 6.02 & 1.83 \\
\hline $\begin{array}{c}\text { Single-detached } \\
(\%)\end{array}$ & 44.79 & 29.60 & 14.34 & 14.64 & 41.06 & 27.31 \\
\hline
\end{tabular}

In order to show differences amongst the three regions under study, some descriptive statistics for the population of each metropolitan region as a whole are reported in Table 1 . The dependent variable, the percentage of people who regularly walk or bike to work, is highest in Montreal at 9\% of the population, and just over 6\% in Toronto and Vancouver. Singledetached homes are over $40 \%$ in the latter two cities, while only $14 \%$ in Montreal. Income is also significantly higher in Toronto and Vancouver than in Montreal. Vancouver has the lowest population density and amount of pre-WWII housing, while Montreal has the highest of both. Finally, the percent of people under 35 years is similar in all three cities, ranging between $40 \%$ and $44 \%$.

\section{$5.2 \quad$ Results}

The results from the nine models described in the previous section are reported in Table 2, grouped first by city and then by land use mix variable. The $\mathrm{R}^{2}$ values, displayed at the bottom of the models, show that the degree to which variation in the proportion walking and biking is explained changes only slightly when entropy is added to the base model $(0.67 \%, 0.87 \%$, and $3.47 \%$ increases for the three cities, respectively), but drastically when interaction is used as the land use mix variable (26.05\%, 11.36\%, and $12.11 \%$ increases). The changes in $\mathrm{t}$ statistics for the three models are also very telling. While the entropy index is always statistically significant, its prominence 
in the model is markedly low. The interaction variable, on the other hand has the highest $\mathrm{t}$-statistic in Toronto and Vancouver of all the independent variables, and is second-highest in Montreal. The coefficients are also much higher for interaction than for entropy, which are made comparable by the use of their $\mathrm{Z}$-scores rather than their actual values.

Furthermore, what can also be drawn from the models is the difference in what independent variables are important between the three cities. In terms of land use mix, the interaction measure improves the model fit most drastically in Toronto while in Montreal the difference is the lowest in all aspects (though it should be mentioned that interaction is still an improvement over the entropy index in Montreal). Aside from land use mix, the most important variable in Toronto, Montreal, and Vancouver in explaining walking and biking is the percentage of houses built before 1946 (World War II). Popu- lation density shows a marked decrease in explanatory power in all three cities, though it is still fairly powerful in the Vancouver model. Another interesting finding is that the percentage of people under 35 years of age has the expected effect in Montreal (albeit statistically insignificant), with more young people contributing to more walking, while in Toronto and Vancouver, the effect is the opposite. This peculiarity disappears in Toronto, however, when the interaction variable is used. While there may be a way of explaining this, the variable was insignificant in Montreal and Toronto, and does not seem to be a very powerful indicator of walking and biking. The percentage of single-detached houses has the strongest effect in Toronto, but is relatively weak in Montreal. Similarly, income is only a powerful variable in Montreal, where lower income areas are indicative of more walking and biking.

Table 2 OLS models on percentage active transport as primary mode for work trips at the census tract level

\begin{tabular}{|c|c|c|c|c|c|c|}
\hline \multicolumn{7}{|c|}{ Toronto } \\
\hline \multirow[t]{2}{*}{ Variable } & \multicolumn{2}{|c|}{ No mix variable } & \multicolumn{2}{|c|}{ Entropy } & \multicolumn{2}{|c|}{ Interaction } \\
\hline & $\beta$ & $\mathrm{t}$ & $\beta$ & $\mathrm{t}$ & $\beta$ & $\mathrm{t}$ \\
\hline Pop. Density $\left(\mathrm{km}^{2}\right)$ & 2.48 & 4.79 & 2.74 & 5.15 & $0.93^{\star \star}$ & 1.86 \\
\hline$<35$ years & -0.039 & -1.13 & \begin{tabular}{l|l}
-0.025 \\
\end{tabular} & -0.73 & 0.049 & 1.50 \\
\hline Pre-WWII & 0.14 & 12.65 & 0.14 & 12.55 & 0.10 & 9.70 \\
\hline Income $(\$ 10,000)$ & 0.0017 & 1.5 & 0.0017 & 1.56 & $0.0023^{*}$ & 2.20 \\
\hline Single-detached & -0.081 & -7.34 & -0.074 & -6.45 & -0.043 & -4.04 \\
\hline Entropy $(\mathrm{Z})$ & \multicolumn{2}{|l|}{ 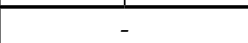 } & $0.0046^{*}$ & 2.04 & \multicolumn{2}{|c|}{-} \\
\hline Interaction $(\mathrm{Z})$ & \multicolumn{2}{|c|}{-} & \multicolumn{2}{|c|}{-} & 0.031 & 12.01 \\
\hline Constant & 0.074 & 4.33 & 0.063 & 3.55 & -0.068 & -3.46 \\
\hline Adjusted $\mathrm{R}^{2}$ & \multicolumn{2}{|c|}{0.3271} & \multicolumn{2}{|c|}{0.3293} & \multicolumn{2}{|c|}{0.4123} \\
\hline \multicolumn{7}{|c|}{ Montreal } \\
\hline \multirow[t]{2}{*}{ Variable } & \multicolumn{2}{|c|}{ No mix variable } & \multicolumn{2}{|c|}{ Entropy } & \multicolumn{2}{|c|}{ Interaction } \\
\hline & $\beta$ & $\mathrm{t}$ & $\beta$ & $\mathrm{t}$ & $\beta$ & $\mathrm{t}$ \\
\hline Pop. Density $\left(\mathrm{km}^{2}\right)$ & 2.93 & 4.71 & 3.04 & 4.89 & $1.04^{\star *}$ & 1.69 \\
\hline$<35$ years & 0.0079 & 0.2 & 0.015 & 0.38 & 0.052 & 1.39 \\
\hline Pre-WWII & 0.21 & 15.55 & 0.21 & 15.05 & 0.16 & 10.85 \\
\hline Income $(\$ 10,000)$ & -0.0066 & -4.8 & -0.0065 & -4.77 & -0.0047 & -3.58 \\
\hline Single-detached & -0.034 & -1.31 & -0.018 & -0.67 & 0.010 & 0.42 \\
\hline Entropy $(\mathrm{Z})$ & \multicolumn{2}{|r|}{ 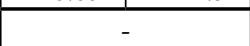 } & 0.0068 & 2.83 & \multicolumn{2}{|c|}{-} \\
\hline Interaction $(\mathrm{Z})$ & \multicolumn{2}{|l|}{ 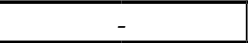 } & \multicolumn{2}{|c|}{-} & 0.033 & 10.08 \\
\hline Constant & 0.076 & 4.66 & 0.071 & 4.33 & 0.062 & 3.99 \\
\hline Adjusted $\mathrm{R}^{2}$ & \multicolumn{2}{|c|}{0.4815} & \multicolumn{2}{|c|}{0.4857} & \multicolumn{2}{|c|}{0.5362} \\
\hline \multicolumn{7}{|c|}{ Vancouver } \\
\hline \multirow[t]{2}{*}{ Variable } & \multicolumn{2}{|c|}{ No mix variable } & \multicolumn{2}{|c|}{ Entropy } & Intera & \\
\hline & $\beta$ & $\mathrm{t}$ & $\beta$ & $\mathrm{t}$ & $\beta$ & $\mathrm{t}$ \\
\hline Pop. Density $\left(\mathrm{km}^{2}\right)$ & 10.09 & 13.36 & 10.52 & 14.13 & 3.46 & 3.37 \\
\hline$<35$ years & $-0.1^{\star}$ & -2.44 & $-0.078^{\star *}$ & -1.94 & -0.060 & -1.59 \\
\hline Pre-WWII & 0.15 & 7.3 & 0.15 & 7.46 & 0.14 & 7.13 \\
\hline Income $(\$ 10,000)$ & -0.0016 & -0.79 & -0.0014 & -0.72 & -0.00068 & -0.37 \\
\hline Single-detached & $-0.036^{*}$ & -2.38 & \begin{tabular}{|l|}
-0.019 \\
\end{tabular} & -1.27 & -0.040 & -2.88 \\
\hline Entropy $(\mathrm{Z})$ & & - & 0.011 & 4.48 & & \\
\hline Interaction $(\mathrm{Z})$ & 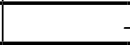 & - & - & & 0.033 & 8.74 \\
\hline Constant & 0.078 & 3.91 & 0.06 & 2.97 & 0.086 & 4.64 \\
\hline Adjusted $\mathrm{R}^{2}$ & 0.5 & 655 & 0.58 & & 0.6 & \\
\hline
\end{tabular}




\section{Discussion and conclusions}

This work presents a first step towards conceptualizing a new manner of measuring land-use mix that is arguably more applicable to land use, transportation, and public health studies than those currently in wide use. The results clearly show that, while controlling for census-tract level demographic and built form factors, land use interactions explain more variation in walking and cycling behavior than existing methods. This suggests that the focus that the entropy index places on balance of land uses is misplaced, and that equal proportions of uses are somewhat arbitrary in predicting travel outcomes. The interaction method, on the other hand, is useful in capturing the degree to which complementary land uses actually meet, which was shown in this paper to have a greater effect on the explanatory power of land use mix when modeling walking and cycling.

The subtlety of measuring land use mix is a complex and important topic that, though widely studied, has much room for improvement. One important goal for land use and transportation planning is finding measures that more accurately and efficiently measure land use mix for particular travel outcomes or trip purposes. Perhaps specific land use mixes would impact travel for different trip purposes. For example, while the presence of parks might not impact work trips, it might play an important role in generating leisure and social trips.

In addition to using more relevant travel outcomes, such as pedestrian counts and non-work walking trips from origin/ destination surveys, further refinement of the actual technique could be explored. For example, certain interactions (e.g., residential/commercial) might yield a greater impact on travel outcomes than others (e.g., industrial/water). Weighting different types of interactions could increase the explanatory power of the interaction method in these types of models. It is hoped that this analysis will add to the ongoing discussion and refinement of this essential topic across the many fields that it touches.

\section{$7 \quad$ Acknowledgements}

The authors wish to acknowledge Prof. Ahmed El-Geneidy and Prof. Nancy Ross for assisting with the paper's framework and for providing useful feedback on the direction of the research. This research was partly funded by the Fonds québécois de recherche sur la société et la culture (FQRSC). Thanks also to the anonymous reviewers whose input greatly improved the paper.

\section{References}

Badoe, D. A. and E. J. Miller (2000). "Transportation-landuse interaction: Empirical findings in North America, and their implications for modeling." Transportation Research Part D: Transport and Environment 5(4): 235-263.

Bhat, C. and R. Gossen (2004). "A mixed multinomial logit model analysis of weekend recreational episode type choice." Transportation Research Part B 38(9): 767-787.

Boarnet, M. and M. Greenwald (2000). "Reproducing other urban areas' empirical test results in Portland, Oregon." Transportation Research Record(1722): 27-37.

Brown, B., I. Yamada, et al. (2009). "Mixed land use and walkability: Variations in land use measures and relationships with BMI, overweight, and obesity." Health and Place 15(4): 1130-1141.

Brownson, R. C., C. M. Hoehner, et al. (2009). "Measuring the built environment for physical activity: State of the science." American Journal of Preventive Medicine 36(4): S99S123.

Cerin, E., E. Leslie, et al. (2007). Applying GIS in physical activity research: Community 'walkability' and walking behaviors. GIS for Health and the Environment: Development in the Asia-Pacific Region With 110 Figures. P. C. Lai and A. S. H. Mak. Berlin, Springer.

Cervero, R. and K. Kockelman (1997). "Travel demand and the 3D's: Density, diversity and design." Transportation Research Part D: Transport and Environment 2(3): 199-219.

City of Los Angeles (2008). Long range transportation plan. City of Montreal (2005). Montreal Master Plan.

City of Toronto (2006). Toronto Official Plan.

Clifton, K., C. Burnier, et al. (2009). "Severity of injury resulting from pedestrian-vehicle crashes: What can we learn from examing the built environment? ." Transportation Research Part D: Transport and Environment 14: 425-436.

DMTI Spatial (2007). CanMap ${ }^{\circledR}$ Streetfiles. Markham, DMTI Spatial.

Frank, L. and G. Pivo (1994). "Impacts of mixed use and density utilization of three modes of travel: single-occupant vehicle, transit, and walking." Transportation Research Record 1466: 44 - 52.

Frank, L. and G. Pivo (1994). "Impacts of mixed use and density utilization of three modes of travel: single-occupant vehicle, transit, and walking." Transportation Research Re$\operatorname{cord}(1466): 44-52$.

Frank, L. D., J. F. Sallis, et al. (2009). "The development of a walkability index: Application to the neighborhood quality of life study." British Journal of Sports Medicine 44(13): 924-933. 
Frank, L. D., T. L. Schmid, et al. (2005). "Linking objectively measured physical activity with objectively measured urban form: findings from SMARTRAQ." American Journal of Preventative Medicine 28(2): 117 - 25.

Handy, S. (2008). "Regional transportation planning in the US: An examination of changes in technical aspects of the planning process in response to changing goals." Transport Policy 15(2): 113-126.

Hess, P. M., A. V. Moudon, et al. (2001). "Measuring Land Use Patterns for Transportation Research.” Transportation Research Record: Journal of the Transportation Research Board 1780: 17-24.

Kerr, J., L. Frank, et al. (2007). "Urban form correlates of pedestrian travel in youth: Differences by gender, race-ethnicity and household attributes." Transportation Research Part D: Transport and Environment 12(3): 177-182.

Kockelman, K. M. (1997). "Travel behavior as function of accessibility, land use mixing, and land use balance: Evidence from San Francisco Bay Area." Transportation Research Record: Journal of the Transportation Research Board 1607: 116-125.

Lee, C. and A. V. Moudon (2004). "Physical activity and environment research in the health field: Implications for urban and transportation planning practice and research." Journal of Planning Literature 19(2): 147-181.

Lee, C. and A. V. Moudon (2006). "Correlates of Walking for Transportation or Recreation Purposes." Journal of Physical Activty and Health 3: S77 - S98.

Murphy, M., A. Nevill, et al. (2002). "Accumulating brisk walking for fitness, cardiovascular risk, and psychological health." Medicine \& Science in Sports \& Exercise 34(9): 1468-1474.

Ordover, J., A. Sykes, et al. (1982). "Herfindahl concentration, rivalry, and mergers." Harvard Law Review 95(8).

Rajamani, J., C. R. Bhat, et al. (2003). "Assessing impact of urban form measures on nonwork trip mode choice after controlling for demographic and level-of-service effects." Transportation Research Record: Journal of the Transportation Research Board 1831: 158-165.

Rippe, J., A. Ward, et al. (1988). "Walking for health and fitness." The Journal of the American Medical Association 259(18): 2720-2724.

Ritsema Van Eck, J. and E. Koomen (2008). "Characterising urban concentration and land-use diversity in simulations of future land use." Annals of Regional Science 42: 123-140.

Shannon, C. (1948). "A mathmatical theory of communication." Bell System Technical Journal 27: 379-423.

StatsCan. (2006). "Canadian Census." from www.chass. utoronto.ca.
Wilkinson, R. and M. Marmot (2003). The Solid Facts: Social Determinants of Health, World Health Organization. 